\title{
$\mathrm{P} 2 \mathrm{P}$ 스트리밍 시스템을 위한 TTL 기반 피어 그룹핑 기법
}

\author{
김 태 영*, 김 은 삼*
}

\section{A TTL-based Peer Grouping Scheme for P2P Streaming Systems}

\author{
Taeyoung Kim*, Eunsam Kim*
}

\section{요 약}

본 논문에서는 P2P 기반의 IPTV 시스템에서 TTL을 이용해서 지역성을 반영하는 피어 그룹핑 기법을 제안한 다. 이 기법은 두 피어 사이의 경유 라우터 수를 최소화하도록 이웃 피어를 선정하여 중간 라우터들이 전송해야 하 는 데이터 양이 감소한 만큼 네트워크 대역폭을 절약할 수 있다. 또한 본 논문에서 제안하는 TTL 기반의 피어 그룹 핑 기법이 기존의 RTT 기반의 기법에 비해 성능이 향상되는 것을 보이기 위해 다양한 시뮬레이션 시험을 수행하였 다. 실험 결과는 본 논문에서 제안하는 TTL 기반의 피어 그룹핑 기법이 전체 라우터들이 전송하는 데이터 및 제어 패킷 용량뿐만 아니라 지터 비율도 감소시킬 수 있다는 것을 보인다.

- Keyword : P2P 스트리밍, IPTV 시스템, 지역성 기반 오버레이 네트워크, ㄲㄴ 기반 피어 그룹핑

\section{Abstract}

In this paper, we propose a new peer grouping scheme to consider locality among peers using TTL values in P2P-based IPTV systems. This scheme can select neighbor peers to minimize the number of intermediate routers between each pair of peers. Thus, it can save the network bandwidth as much as the amount of data that the reduced number of routers should transmit In addition, we have conducted various simulation experiments to show that our proposed TTL-based peer grouping scheme can outperform the conventional RTT-based grouping scheme. The

- 제1저자 : 김태영 교신저자 : 김은삼

• 투고일 : 2011. 10. 26., 심사일 : 2011. 11. 23, 게재확정일 : .2011. 12. 23

* 홍익대학교 컴퓨터공학과(Dept. of Computer Engineering, Hongik University)

※ 이 논문은 2011년 정부(교육과학기술부)의 재원으로 한국연구재단의 기초연구사업(No. 2011-0002563) 및 2011 학년도 홍익대학교 학술연구진흥비 지원으로 수행되었음. 
experimental results show that our proposed scheme can reduce the jitter ratio as well as the number of data and control packets that all routers should transmit.

- Keyword: P2P Streaming, IPTV systems, Locality-aware overlay network, TTL-based peer grouping

\section{I. 서 론}

네트워크의 광역화와 디지털 기술의 발전으로 $\mathrm{IP}$ 네트워 크 기반으로 실시간 방송과 $\mathrm{VOD}$ 등의 서비스를 제공하는 방송과 통신을 융합한 IPTV 서비스가 등장하였다[1]. 최근 IPTV 서비스의 규모가 급격히 커지면서 높은 설치비용으로 인해 확장성(scalability)이 현저히 떨어지는 기존의 $\mathrm{CDN}$ (Content Distribution Network) 구조의 대안으로 높은 확장성을 갖추고 낮은 설치비용으로 구현이 가능한 $\mathrm{P} 2 \mathrm{P}$ 기반의 스트리밍 시스템이 주목받고 있다[2,3]

이러한 P2P 기반의 스트리밍 방식은 기존의 클라이언트서버 방식과 달리 각 피어가 저장하고 있는 데이터를 다른 피어와 공유해야 하므로 자신과 연결된 피어들 간의 네트워 크 상태가 서비스 품질을 좌우하게 된다. 특히 연결된 피어 의 위치가 가까울수록 데이터가 도착 시간이 줄어들고 분실 가능성도 감소한다. 이에 따라 P2P 스트리밍을 위한 오버레 이 네트워크를 구성할 때 피어 간의 물리적인 거리나 지연 시간을 나타내는 지역성을 고려하는 것이 필수적이다.

따라서 지역성을 기반으로 오버레이 네트워크를 구성하 여 동일 지역 내에서 우선적으로 검색과 전송이 수행되게 하 는 많은 기법들이 제안되었다[4,5,6,7,8,9,10,11,12,13] 대부분의 이런 기법들은 RTT(Round Trip Time) 값을 이 용하여 피어 간의 물리적인 거리를 측정하였다. RTT 값은 네트워크 지연 시간을 측정하므로 적은 양의 데이터를 전송 하는 경우에는 중간 라우터들이 중계하는 데이터 양이 적기 때문에 중간 라우터 수가 많더라도 네트워크 부하에 거의 영 향을 주지 않는다. 하지만 비디오를 재생하는 동안 장시간 많은 데이터를 전송해야 하는 IPTV 서비스의 경우에는 데 이터를 중계해야 하는 중간 라우터 수에 따라 전체 네트워크 부하에 상당한 영향을 줄 수 있다.
표 1. 국내와 미국 대학과의 RTT 및 중간 라우터 수 Table 1. RTT values and the number of intermediate routers between a domestic and US universities

\begin{tabular}{|c|c|c|}
\hline & RTा 값(ms) & $\begin{array}{c}\text { 중간 } \\
\text { 라우터 수(개 }\end{array}$ \\
\hline R 대학교 & 224 & 26 \\
\hline F 대학교 & 235 & 19 \\
\hline N 대학교 & 243 & 22 \\
\hline P 대학교 & 258 & 21 \\
\hline C 대학교 & 261 & 28 \\
\hline
\end{tabular}

<표 1>은 국내에서 미국에 있는 5 개 대학교들과의 RTT 값과 중간 라우터 수를 측정한 결과이다. RTT 값을 기반으 로 지역성을 반영하는 경우에는 5 개 학교 중에서 $\mathrm{R}$ 대학교 가 이웃 피어로 선정될 것이다. 하지만 R 대학교의 RTT 값 이 $\mathrm{F}$ 대학교보다 단지 $11 \mathrm{~ms}$ 작고 중간 라우터 수는 7 개 더 많다는 것을 알 수 있다. 이에 따라 비디오가 재생되는 장시 간동안 R 대학교와의 사이 있는 중간 라우터들이 중계해야 하는 데이터 양이 늘어나서 네트워크 대역폭 사용이 상대적 으로 증가하게 된다.

따라서 본 논문에서는 TTL(Time To Live) 값을 이용 해서 지역성을 반영하는 피어 그룹핑 기법을 제안한다. 이 기법에서는 TTL 값을 기반으로 두 피어 사이의 중간 라우 터 수를 최소화하도록 이웃 피어를 선정함으로써 기존 RTT 기반의 그룹핑 기법에 비해 중간 라우터들이 중계해야 하는 데이터 양을 상당히 감소시킬 수 있다. 일반 네트워크 응용 에서는 서비스 지연 시간이 성능의 가장 중요한 요소 중 하 나이다. 따라서 짧은 시간 내에서의 지연 시간을 기준으로 보면 RTT와 TTL을 고려한 경우의 성능 차이가 거의 없을 것이다. 하지만 본 논문에서는 장시간 지속적으로 많은 데이 터가 전송되어야 하는 P2P 스트리밍 시스템의 특성으로 인 해 TTL 기반의 그룹핑 기법이 우수한 성능을 보인다.

마지막으로 실험을 통해서 본 논문에서 제안하는 TTL 기 반의 피어 그룹핑 기법에서 중간 라우터들이 전송해야 하는 데이터를 감소한 양만큼의 네트워크 대역폭이 절약되고 전 송 지연 시간 및 분실 가능성도 감소시킬 수 있다는 것을 보 
인다. 또한 피어 간의 중간 라우터 수를 줄임으로써 기존의 $\mathrm{P} 2 \mathrm{P}$ 실시간 스트리밍 시스템에서의 성능 평가 기준인 초기 재생 지연 시간과 서버와의 재생 시점 차도 약간 향상된다는 것을 보인다.

본 논문은 다음과 같이 구성된다. 2장에서는 기존 $\mathrm{P} 2 \mathrm{P}$ 스트리밍 시스템과 RTT를 사용하여 지역성을 고려하는 관 련 연구에 대해 기술한다. 3장에서는 본 논문에서 제안하는 TTL 기반의 피어 그룹핑 기법과 기존 RTT 기반의 그룹핑 기법을 비교하여 기술한다. 4장에서는 본 논문에서 제안하 는 TTL 기반의 그룹핑 기법과 기존 RTT 기반 그룹핑 기법 의 성능을 실험을 통해 비교 분석한다. 마지막으로 5 장에서 는 결론을 기술한다.

\section{II. 관련연구}

$\mathrm{P} 2 \mathrm{P}$ 스트리밍 시스템은 가상의 오버레이 네트워크를 이 용하여 피어 간에 비디오를 양방향으로 전송하는 방식으로 서 크게 트리 구조와 메시 구조로 분류될 수 있다.

초기에 제안된 트리 구조[14,15,16]는 각 피어가 서비 스에 가입하거나 탈퇴할 때마다 트리를 새롭게 구성해야 하 는 오버헤드가 발생하였다. 이러한 문제를 해결하기 위해 제 안된 메시 기반의 P2P 스트리밍 시스템[17,18,19,20]에 서는 트리와 같은 특정 구조를 구성하지 않고 각 피어가 저 장하고 있는 데이터에 대한 정보인 버퍼맙(buffer map)을 이웃 피어들과 교환함으로써 자신이 필요한 데이터를 파악 해서 이웃 피어들에게 특정 데이터 전송을 요청한다. 이와 같이 메시 기반의 구조에서는 각 피어가 이웃 피어들과 데이 터를 서로 전송해야 하므로 P2P 오버레이 네트워크를 구성 할 때 피어 간의 지연 시간을 줄이기 위해 지역성을 파악하 는 여러 기법들이 제안되었다.

먼저 GeoPing, GeoCluster, GeoTrack 등으로 구성된 $\mathrm{IP} 2 \mathrm{GEO}$ 이 제안되었다[4]. GeoPing은 넓게 골고루 분포 된 클라이언트로부터 피어와의 거리를 ping 명령어를 사용 해서 RTT 값을 측정하는 방법이다. GeoCluster는 BGP 라우팅 테이블을 참조하여 지역적인 클러스터를 구성한 후 GeoPing을 이용해 거리를 측정한다. GeoTrack은 호스트 와 가장 가까운 라우터의 위치를 이용해서 대략적인 위치를 추정하는 방법이다. 또한, 기준이 되는 랜드마크 노드들을 지정하여 접속된 호스트와의 RTT값을 구해서 위치를 파악 하는 Global Network Positioning(GNP)[5]와 Topo logy-based Geolocation (TBG)[6]도 제안되었다. 이 외 에도 NetGeo[7], IP2Location [8], MaxMind[9]는 실
제 인터넷에서 서비스 되는 방식으로 데이타베이스에 저장 된 지역정보를 통해 지역성을 파악하는 기법이다.

또한, 위와 같은 지역성을 측정하는 방법을 통해 피어 그 룹핑을 수행하는 기법들도 제안되었다. LTM[10]에서는 가 장 인접한 피어들을 이웃 피어로 관리하면서 주기적으로 $\mathrm{RTT}$ 값을 토대로 가장 먼 피어를 라우팅 테이블에서 제거 하면서 그룹을 유지한다. 또한 SLUP[11]에서는 모든 피 어들을 물리적인 거리에 따라 도메인으로 나누어서 그룹핑 을 수행한다. 요청 피어로부터 질의가 발생할 경우 물리적으 로 인접한 순서로 요청을 전달한다. 이외에도 지역성을 고려 할 때 피어 간의 거리를 RTT 값을 기준으로 측정하는 여러 논문들이 제안되었다 [12,13].

하지만 이러한 연구들은 대부분 두 피어 사이의 거리를 RTT 값을 통해 네트워크 지연 시간을 기준으로 파악하며 두 피어 간 중간 라우터 수는 전혀 고려하지 않았다. 본 논 문에서는 IPTV와 같이 장시간 많은 양의 데이터를 전송해 야 하는 환경에서 기존의 RTT 값이 아닌 TTL 값을 이용해 서 피어 그룹핑을 수행하는 기법을 제시함으로써 전체 네트 워크에 발생하는 부하가 줄어들고 그 만큼 전송 지연 시간 및 지터 비율도 감소하게 된다.

\section{TTL 기반 그룹핑 기법}

본 장에서는 $\mathrm{P} 2 \mathrm{P}$ 메시 구조 기반의 오버레이 네트워크를 구성할 때 요청 피어와 지역적으로 가장 가까운 피어를 선정 하기 위해 기존의 RTT를 이용하는 그룹핑 기법과 본 논문 에서 제안하는 TTL을 이용하는 그룹핑 기법에 대해 기술한다.

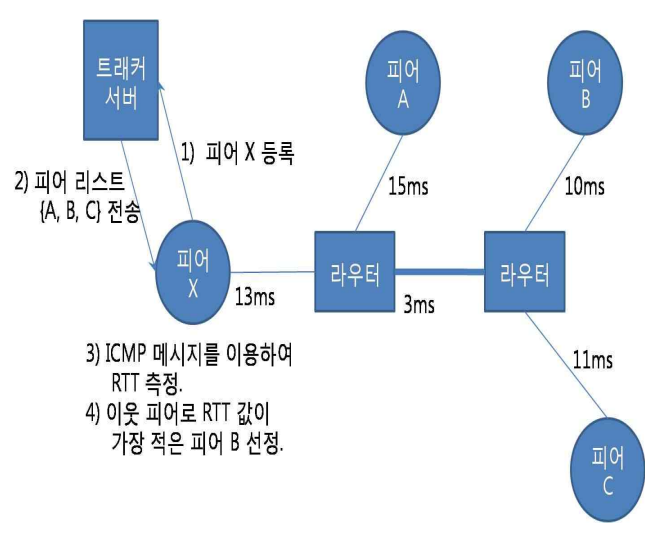

그림 1. RTT을 시용한 이웃 피어 선정 절차 Fig 1. Procedure of selecting neighbor peers using RTTs 


\section{1 기존 RTT 기반의 피어 그룹핑 기법}

$\mathrm{RTT}$ 기반의 피어 그룹핑 기법은 지역성을 고려하는 대 부분의 기존 $\mathrm{P} 2 \mathrm{P}$ 메시 구조에서 사용되고 있는 기법이다. 트래커 서버를 이용해서 피어 검색을 수행한 후에 요청 피어 와 각 피어와의 RTT 값을 이용하여 지역성을 파악한다. $\mathrm{RTT}$ 값이 가장 작은 피어가 지역적으로 가장 가까운 것으 로 판단해서 이웃 피어로 선정하여 그룹핑을 수행한다.

<그림 1>은 이 기법이 동작하는 방식을 구체적으로 보여 주고 있다. 그림에서 피어와 라우터 사이 시간은 데이터 전 송 지연 시간을 의미한다. 먼저 피어 $\mathrm{X}$ 가 트래커 서버에게 가입 메시지를 전송하고 트래커 서버는 현재 피어 $\mathrm{X}$ 에게 서 비스를 제공할 수 있는 피어들의 리스트 $\{\mathrm{A}, \mathrm{B}, \mathrm{C}\}$ 를 피어 $\mathrm{X}$ 에게 전송한다. 피어 $\mathrm{X}$ 는 트래커 서버로부터 전달받은 리 스트에 있는 피어들에게 각각 $\mathrm{ICMP}$ (Internet Control Message Protocol) 메시지를 전송한 후 회신된 ICMP를 통해 피어들 중에서 RTT 값이 가장 적은 피어를 이웃 피어 로 선정한다. <그림 $1>$ 에서는 피어 $\mathrm{X}$ 와 피어 $\mathrm{A}, \mathrm{B}, \mathrm{C}$ 와의 $\mathrm{RTT}$ 값이 각각 $56 \mathrm{~ms}, 52 \mathrm{~ms}, 54 \mathrm{~ms}$ 이므로 그 중 가장 작 은 RTT 값이 측정된 피어 $\mathrm{B}$ 를 이웃 피어로 선정한다.

이 후에는 기존 $\mathrm{P} 2 \mathrm{P}$ 메시 구조에서와 같이 버퍼맵을 이 웃 피어들과 교환함으로써 필요한 데이터를 파악하고 데이 터 전송을 요청한다.

\subsection{TTL 기반의 피어 그룹핑 기법}

TTL 기반의 피어 그룹핑 기법은 본 논문에서 제안하는 이웃 피어 선정 방식으로서 기존의 RTT 대신 TTL을 이용 하여 이웃 피어를 선정한다. 즉, 두 피어 간의 중간 라우터 수가 가장 적은 피어를 선정하기 위해 트래커 서버에서 전송 받은 피어 리스트 중에서 TTL 값이 가장 큰 피어를 이웃 피 어로 선정한다.

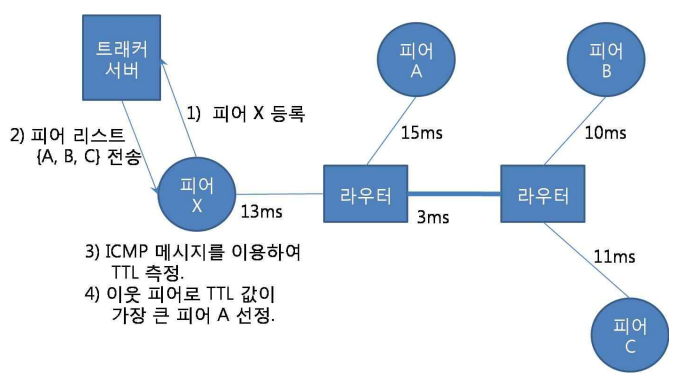

그림 2. TाL을 이용한 이웃 피어 선정 절차 Fig 2 Procedure of selecting neighbor peers using TTLs
표 2. Tा를 시용한 이웃 피어 선정 절차

Table 2. Procedure of selecting neighbor peers using TTS

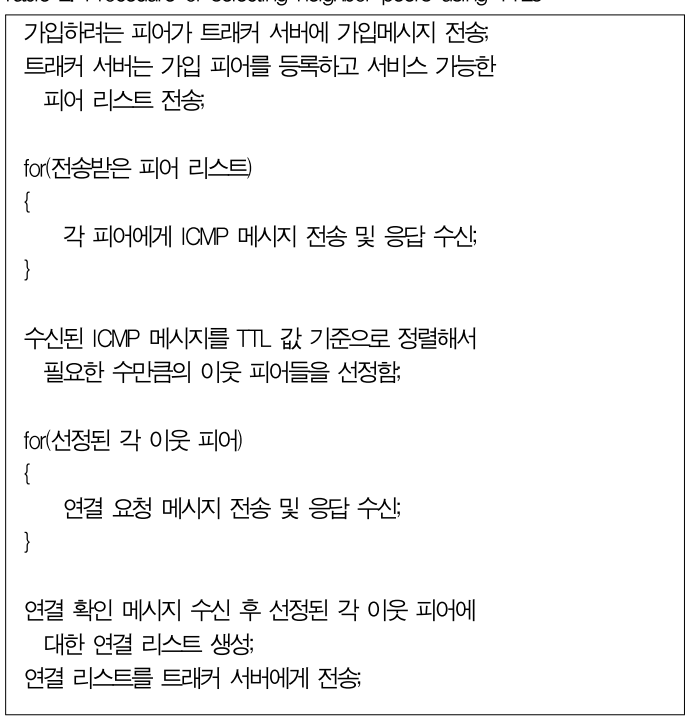

<그림 2>는 이 기법이 동작하는 방식을 보여주고 있다. TTL 값을 측정하기 위해 모든 라우터는 각 패킷의 TTL 값 을 1 만 감소시키며 TTL 값을 확인하기 위한 ICMP(Internet Control Message Protocol) 프로토콜을 지원한다고 가정한다. RTT 기반의 그룹핑 기법과 마찬가지 로 먼저 피어 $\mathrm{X}$ 가 트래커 서버로 가입 메시지를 전송하고 트 래커 서버는 현재 요청 피어에게 서비스 제공 가능한 피어 리스트를 피어 $\mathrm{X}$ 에게 전송한다. 이 후 피어 $\mathrm{X}$ 는 리스트에 있는 각 피어에게 $\mathrm{ICMP}$ 메시지를 전송한 후 회신된 $\mathrm{ICMP}$ 를 통해 각 피어와의 TTL 값을 파악한다. 이 중 가장 큰 TTL 값을 가진 피어를 이웃 피어로 선정한다. <그림 2> 에서는 피어 A가 TTL 값이 하나의 라우터와 하나의 호스트 를 경유하므로 $126(=128-2)$ 이 되어 가장 크기 때문에 피 어 $\mathrm{A}$ 를 이웃 피어로 선정한다. TTL을 사용해서 이웃 피어 를 선정하는 자세한 절차는 <표 2>에 기술되어 있다.

3.3 RTT 및 TTL 기반의 피어 그룹핑 기법 비교 $\mathrm{RTT}$ 값은 특정 시점의 네트워크 상태를 반영하여 지연 시간을 기준으로 측정되기 때문에 적은 데이터를 전송하는 기존의 일반적인 응용들에서는 대부분 적합하다. 하지만 RTT 값은 단순히 네트워크 경로 상의 지연 시간만을 반영 하므로 두 호스트 사이에서 데이터를 중계하는 라우터 수는 TTL을 이용한 경우보다 일반적으로 많을 것이다. 따라서 장시간 많은 데이터를 전송해야 하는 IPTV 환경에서는 각 라우터들이 처리해야 데이터 양이 상대적으로 증가하게 된다. 


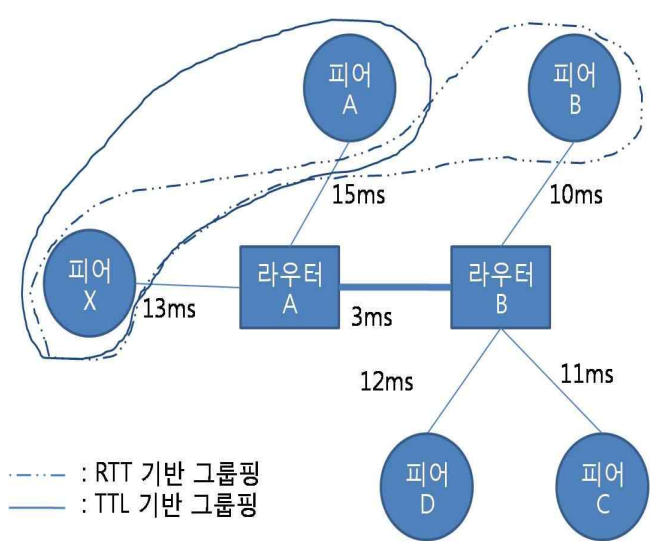

그림 3. RTT 기반 그룹핑 기법과 TTL 기반 그룹핑 기법의 비교 Fig 3. Comparison of RTT and TTL-based grouping schemes

<그림 3>에서 보듯이 TTL 기반으로 이웃 피어를 선정할 경우에는 라우터 $\mathrm{A}$ 만이 데이터 전송에 참여한다. 반면, RTT를 고려해서 이웃 피어를 선정하는 경우에는 라우터 A 뿐만 아니라 라우터 $\mathrm{B}$ 도 데이터 전송에 참여해야 한다. 이 로 인해 피어 $\mathrm{C}$ 와 피어 $\mathrm{D}$ 가 데이터를 전송하는 환경에도 영 향을 줄 수 있게 된다. 즉, 데이터 전송에 참여하는 라우터의 수가 증가함에 따라 전체 네트워크에 부하를 증가시키게 된다.

반면 본 논문에서 제안하는 TTL을 고려한 피어 선정 기 법에서는 두 피어 사이의 중간 라우터 수를 최소화하도록 이 웃 피어를 선정하기 때문에 전체 네트워크에 발생하는 부하 가 줄어들고 그 만큼 전송 지연 시간 및 지터 비율도 감소하 게 된다.

\section{IV. 성능 평가}

이 장에서는 본 논문에서 제안한 TTL 기반의 피어 그룹 핑 기법의 성능을 기존의 RTT 기반의 피어 그룹핑 기법 및 지역성을 고려하지 않은 경우와 비교하여 분석한다. 먼저 실 험 환경 구성에 대해 기술한 후 실험 결과를 설명한다.

표 3. 실험 파라미터

Table 3. Simulation Parameters

\begin{tabular}{|c|c|c|}
\hline \multicolumn{2}{|c|}{ 피어 수 } & 1200개 \\
\hline \multicolumn{2}{|c|}{ 라우터 수 } & 266개 \\
\hline \multicolumn{2}{|c|}{ 실험 시간 } & 80분 \\
\hline $\begin{array}{c}\text { 일반 피어와 } \\
\text { 엣지 라우터 } \\
\text { 간의 대역폭 }\end{array}$ & 10Mbps & 240개 \\
\hline
\end{tabular}

\begin{tabular}{|c|c|c|}
\hline \multirow{4}{*}{} & $20 \mathrm{Mbps}$ & 240개 \\
\cline { 2 - 3 } & $50 \mathrm{Mbps}$ & 600 개 \\
\cline { 2 - 3 } & $100 \mathrm{Mbps}$ & 120개 \\
\hline \multirow{3}{*}{$\begin{array}{c}\text { 라우터 간의 } \\
\text { 대역폭 }\end{array}$} & 1Gbps (엣지 라우터 간) & 250개 \\
\cline { 2 - 3 } & $\begin{array}{c}\text { 3Gbps } \\
\text { (엣지와 코어 라우터 간) }\end{array}$ & 10 개 \\
\cline { 2 - 3 } & 5Gbps (코어 라우터 간) & 6 개 \\
\hline \multicolumn{2}{|c|}{ 서버의 최대 일반 피어 연결 수 } & 20개 \\
\hline \multicolumn{2}{|c|}{ 일반 피어의 최대 이웃 피어 수 } & 6 개 \\
\hline
\end{tabular}

\section{1 실험 환경}

본 논문에서는 가상 네트워크 토폴로지를 제공하는 네트 워크 시뮬레이터인 퀄넷(QualNet)을 사용하여 메시 구조 기반의 P2P 스트리밍 시스템에 대한 시뮬레이션을 수행하 였다. 퀄넷의 가상 환경에서 1200 개의 피어와 266 개의 라 우터를 구축하였고 80 분 동안 $\mathrm{P} 2 \mathrm{P}$ 스트리밍 실험을 수행하 였다. 물리적인 네트워크 환경을 실제와 최대한 유사하게 구 성하기 위해 다양하게 분포시켰다. 일반 피어와 라우터 사이 에는 $10 \mathrm{Mbps}$ 에서 $100 \mathrm{Mbps}$ 까지의 대역폭을 설정하였다. 라우터 사이의 대역폭도 라우터의 종류에 따라 $1 \mathrm{Gbps}$ 에서 $5 \mathrm{Gbps}$ 까지 설정하였다. 서버가 직접 푸시 방식으로 데이터 를 전송하는 최대 일반 피어 수는 20개로 설정했고 각 일반 피어가 연결하는 최대 이웃 피어 수는 6 개로 설정했다. 각 피어는 가입과 탈퇴를 반복하는 동적 환경을 구성하였다. 자 세한 실험 파라미터는 <표 3>에 제시되어 있다.

이와 같은 실험 파라미터 값을 기반으로 비디오 재생률을 $360 \mathrm{Kbps}, 540 \mathrm{Kbps}, 720 \mathrm{Kbps}$ 로 변화하면서 피어 간 중 간 라우터 수, 전체 라우터들의 전송 패킷 용량, 지터 (jitter) 비율, 초기 재생 지연 시간(start-up delay) 및 서 버와의 재생 시점 차(lag time)에 대해 비교 분석한다.

\section{2 실험 결과}

4.2.1피어 간 중간 라우터 수

<그림 4>는 데이터 전송 속도에 해당하는 비디오 재생률 을 $360 \mathrm{Kbps}$ 에서 $720 \mathrm{Kbps}$ 까지 증가시키면서 TTL 및 $\mathrm{RTT}$ 기반의 피어 그룹핑 기법과 지역성을 고려하지 않은 경우에 대해 피어간 평균 중간 라우터 수를 비교한 것이다. 재생률을 변화시키더라도 피어를 선정하는 기준은 동일하기 때문에 각 재생률에서 비슷한 결과를 보였다.

$\mathrm{TTL}$ 기반 그룹핑 기법의 경우에는 피어 간에 평균 5.8 
개의 중간 라우터를 경유하여 데이터가 전송되었다. 반면 $\mathrm{RTT}$ 기반 그룹핑 기법과 지역성을 고려하지 않은 경우에는 평균 중간 라우터 수가 각각 6.2 와 6.5개였다. 즉, 본 논문 에서 제안하는 TTL 기반 그룹핑 기법의 평균 중간 라우터 수가 RTT 기반 그룹핑 기법과 지역성을 고려하지 않은 경 우에 비해서 각각 $6.5 \%$ 와 $11 \%$ 적었다. 이와 같은 결과는 네트워크 지연 시간을 기준으로 측정되는 RTT 값에 비해 중간 라우터 수를 기준으로 측정되는 TTL 값을 반영하여 이웃 피어를 선정했기 때문이다.

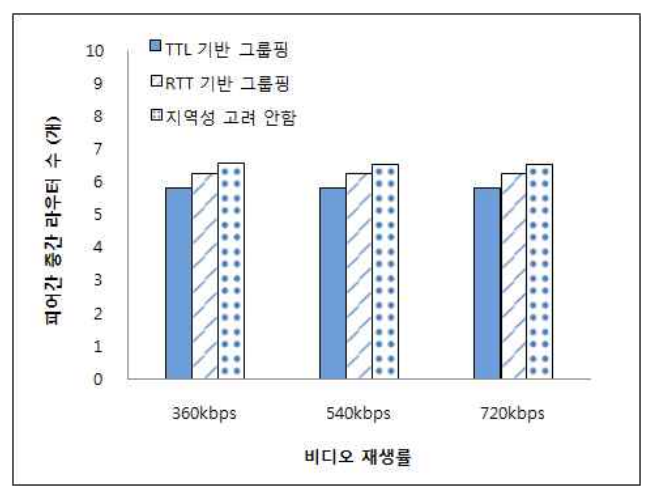

그림 4. 재생률에 따른 평균 중간 라우터 수 Fig 4. Average number of intermedate routers according to video playback rate

이것은 중간 라우터 수가 감소한 만큼 그 라우터들이 전 송해야 하는 데이터 양을 감소시킬 수 있다는 것을 의미하므 로 전체 네트워크 부하를 줄이는 효과가 있다.

\subsection{2 전체 라우터들의 전송 패킷 용량}

<그림 5>는 비디오 재생률을 변경하면서 각 그룹핑 기법 을 이용할 때 전체 라우터들이 전송한 총 데이터 패킷 용량 을 측정한 것이다. <그림 $4>$ 에서 보듯이 사용하는 그룹핑 기 법에 따라 중간 라우터 수에 차이가 있으므로 중간 라우터들 이 전송하는 데이터 패킷의 양도 차이가 발생한다. 〈그림 5> 는 이와 같은 차이를 실험을 통해 보여준다.

예상대로 두 피어 사이에 평균 중간 라우터 수가 적은 순 서대로 전체 라우터들이 전송하는 데이터 패킷의 용량이 적 었다. 즉, TTL 기반 그룹핑 기법, RTT 기반 그룹핑 기법, 지역성을 고려하지 않는 경우의 순으로 라우터들이 전송하 는 데이터 패킷의 용량이 적었다. 예를 들어, 재생률이 $540 \mathrm{Kbps}$ 의 경우에 TTL 기반의 그룹핑 기법에서 전체 라 우터들이 전송한 총 데이터 패킷 용량이 RTT 기반 그룹핑 기법와 지역성을 고려하지 않는 경우에 비해 각각 $10.1 \%$ 와 $16.8 \%$ 적었다. 또한 재생률이 $720 \mathrm{Kbps}$ 로 증가한 경우에
는 TTL 기반 그룹핑 기법이 RTT 기반 그룹핑 기법와 지역 성을 고려하지 않는 경우에 비해 각각 $11.1 \%$ 와 $18.1 \%$ 만 큼 총 데이터 패킷 용량을 감소시켜서 차이가 더욱 증가하였 다. 이것은 네트워크가 혼잡해질수록 본 논문에서 제안하는 $\mathrm{TTL}$ 기반 그룹핑 기법이 더욱 효과적으로 동작한다는 것을 보여준다.

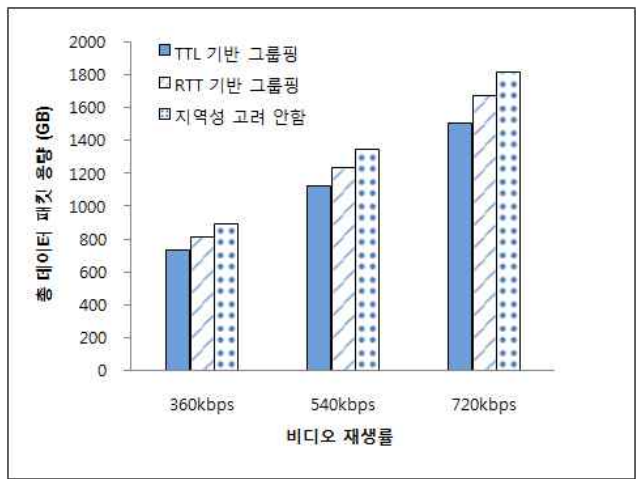

그림 5. 재생률에 따라 전체 라우터들이 전송한 총 데이터 패킷 용량

Fig 5. Total amout of data packets transmitted by all routers according to video playback rate

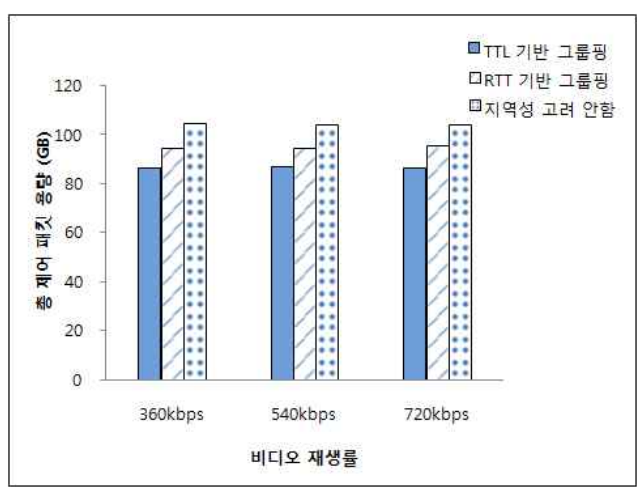

그림 6. 재생률에 따라 전체 라우터들이 전송한 총 제어 패킷 용량 Fig 6. Total amout of control packets transmitted by all routers according to video playback rate

한편 <그림 $6>$ 은 비디오 재생률에 따라 각 그룹핑 기법에 서 전체 라우터들이 전송한 총 제어 패킷 용량을 보여주고 있다. 사용하는 그룹핑 기법에 따른 제어 패킷의 총 용량은 데이터 패킷 용량의 차이와 비슷하게 나타나지만 비디오 재 생률에 따라 제어 패킷의 용량 차이는 없다는 것을 알 수 있 다. 이것은 데이터 패킷과 달리 제어 패킷의 크기는 비디오 재생률과 관계없이 동일한 값을 사용하기 때문이다. 


\subsection{3 지터 비율}

<그림 7>과 <그림 8>은 비디오 재생률에 따라 각 그룹핑 기법에서 총 패킷 중 지터 비율을 나타낸 것이다. 지터 비율 은 분실된 패킷과 재생 마감 시간보다 늦게 도착한 지연 패 킷을 모두 포함한다. 본 실험에서는 전체 네트워크가 충분히 혼잡한 상황에서 세 그룹핑 기법의 차이를 살펴보기 위해 <그림 8 >에서 재생률이 $1.44 \mathrm{Mbps}$ 인 경우를 추가하여 실험 을 수행하였다.

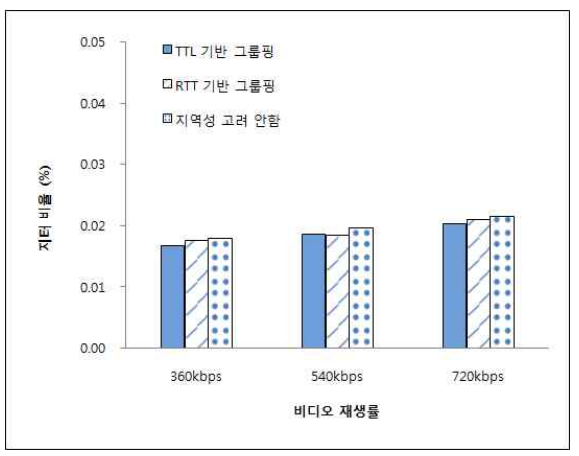

그림 7. 재생률에 따른 평균 지터 비율 Fig 7. Average jitter ratio according to video playback rate

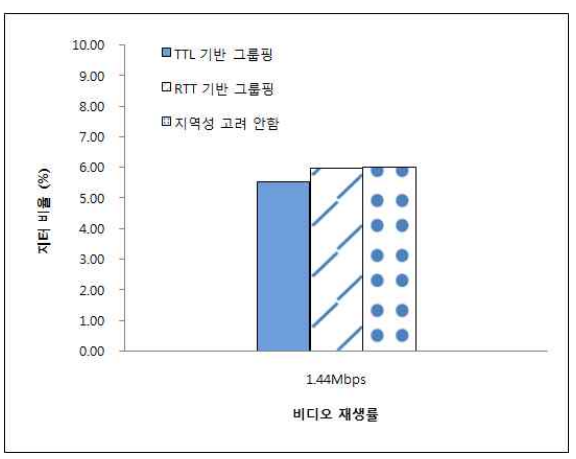

그림 8. 재생률에 따른 평균 지터 비율 Fig 8. Average jitter ratio according to video playback rate

<그림 7>에서 보듯이 재생률이 $360 \mathrm{Kbps}$ 에서 $720 \mathrm{Kbps}$ 까지는 각 기법 모두 네트워크 대역폭이 비교적 여유가 있어 서 TTL 기반 기법이 다른 두 기법에 비해 지터 비율이 상대 적으로 낮지만 차이가 거의 없다. 예를 들어 재생률이 $720 \mathrm{Kbps}$ 의 경우에 TTL 기반 기법에서의 지터 비율이 $\mathrm{RTT}$ 기반 기법과 지역성을 고려하지 않는 경우에 비해 각 각 평균 $0.0007 \%$ 와 $0.0012 \%$ 낮았다. 하지만 <그림 $8>$ 에 서 보듯이 네트워크가 충분히 혼잡해지는 재생률이
$1.44 \mathrm{Mbps}$ 인 경우에는 $\mathrm{TTL}$ 기반 그룹핑 기법에서의 지터 비율이 RTT 기반 기법과 지역성이 없는 기법에 비해 각각 $0.45 \%$ 와 $0.50 \%$ 낮았다. 이것은 TTL 기반 그룹핑 기법이 중간 라우터 수를 줄여서 이들이 전송해야 할 데이터 양을 줄였고 이에 따라 다른 기법에 비해 그 만큼의 네트워크 대 역폭을 상대적으로 절약했기 때문이다.

\subsection{4 초기 재생 지연 시간 및 서버와의 재생 시점 차}

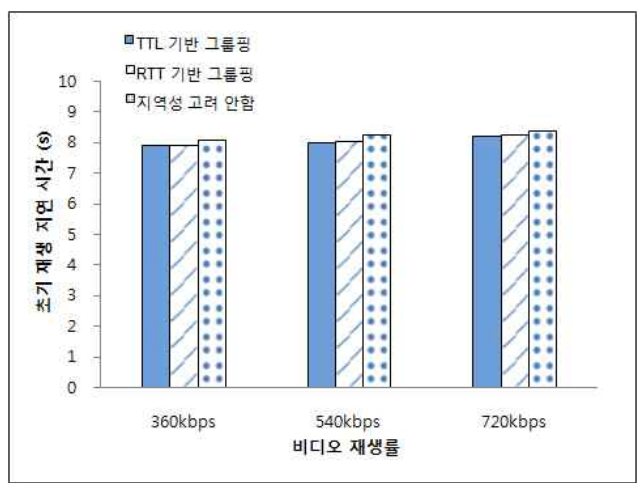

그림 9. 재생률에 따른 평균 초기 재생 지연 시간 Fig 9. Average start-up delay according to video playback rate

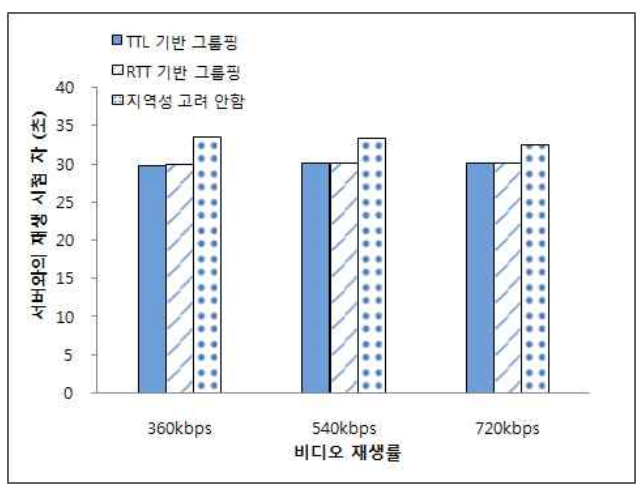

그림 10. 재생률에 따른 서버와의 재생 시점 차 Fig 10. Lag time from a server according to video playback rate

<그림 9>는 재생률에 따라 각 그룹핑 기법의 초기 재생 지연 시간을 보여준다. TTL 기반의 그룹핑 기법이 미세하 지만 RTT 기반의 그룹핑 기법과 지역성을 고려하지 않는 경우보다 초기 재생 지연 시간이 짧다는 것을 알 수 있다. $540 \mathrm{Kbps}$ 재생률의 경우 TTL 기반 기법은 RTT 기반 기법 과 지역성이 없는 기법에 비해 각각 0.05 초와 0.27 초 작은 초기 재생 지연 시간 차를 보였다. 
<그림 10>은 재생률에 따라 서버와의 재생 시점 차를 보 여준다. 각 재생률에서 TTL 기반 기법과 RTT 기반 기법은 각각 30.1초, 30.2초로 미세한 차가 있고 지역성을 고려하 지 않은 기법은 33.5 초의 서버와의 재생 시점 차를 보였다.

이러한 결과들은 본 논문에서 제안하는 TTL 기반 그룹핑 기법이 상대적으로 적은 수의 중간 라우터를 거치기 때문에 라우터에서 발생하는 지연 시간이 적기 때문이다.

이와 같은 실험 결과들을 통해 본 논문에서 제안하는 TTL 기반 그룹핑 기법은 기존의 RTT 기반의 그룹핑 기법 에 비해 P2P 실시간 스트리밍 서비스의 기존 성능 평가 기 준인 초기 재생 지연 시간과 서버와의 재생 시점 차의 성능 이 저하되지 않으면서 네트워크 부하와 지터 비율을 줄일 수 있다는 것을 알 수 있다.

\section{V. 결론}

본 논문에서는 장시간 많은 데이터를 전송해야 하는 IPTV 시스템에서 기존의 RTT 대신 TTL을 이용해서 지역 성을 반영하는 피어 그룹핑 기법을 제안하였다. 이 기법은 TTL 값을 기반으로 두 피어 사이에서 데이터를 중계하는 중간 라우터 수를 최소화할 수 있도록 이웃 피어를 선정한 다. 따라서 중간 라우터들이 전송하는 데이터 양이 감소함으 로써 그 만큼의 네트워크 대역폭을 절약하고 전송되는 데이 터의 지터 비율도 줄였다. 또한 시뮬레이션을 통해 초기 재 생 지연 시간과 서버와의 재생 시점 차의 성능도 미세하게 향상되는 것을 보였다. 또한 향후에는 실시간 방송과 $\mathrm{VOD}$ 등을 포함해서 다양한 고품질의 서비스가 IPTV 시스템에서 제공될 것으로 예측되기 때문에 본 논문에서 제안하는 TTL 기반의 피어 그룹핑 기법이 더 활발히 활용될 수 있을 것으 로 기대된다.

본 논문의 연구 성과를 바탕으로 추후에는 지연 시간 감 소를 통해서 지터 비율을 줄이고 초기 재생 지연 시간과 서 버와의 재생 시점 차를 향상시키기 위해 RTT 값과 TTL 값 을 최적의 비율로 동시에 고려하는 지역성 기법에 대해 연구 를 진행할 계획이다.

\section{참고문헌}

[1] A. Sentinelli, G. Marfia, M. Gerla, L. Kleinrock, an d S. Tewari, "Will IPTV Ride the Peer-to-Peer Stream?", Communications Magazine, IEEE, Volume. 45, Issue. 6, pp. 86-92, Jun. 2007.

[2] J. Kim, D. Kim, E. Kim and S. Pae, "An Efficient Peer-to-Peer Streaming Scheme Based on a Push-Mesh Structure.", Journal of the Korea Society of Computer and Information, Vol. 15, No. 3, pp. 81-89, Mar. 2010.

[3] S. Kim, and E. Kim, "An Energy-Efficient Mobile P2P Streaming Structure Using Agent Peers.", Journal of the Korea Society of Computer and Information, Vol. 16, No. 6, pp. 113-120, Feb. 2011.

[4] V. Padmanabhan, and L. Subramanian. "Deter mining the Geographic Location of Internet Hosts.", Microsoft Research Technical Report MSR-TR-2000-110, Nov. 2000.

[5] E. Ng, and H Zhang. "Predicting Internet Network Distance with Coordinates-Based Approaches.", Proc. of INFOCOM, Volume. 1, pp. 170-179, Jun. 2002.

[6] E Katz-Bassett, J. John, A Krishnamurthy, D. Wetherall, T. Anderson, and Y. Chawathe, "Towards IP geolocation using delay and topology measurements.", The 6th ACM SIGCOMM conference on Intemet measurement (IMCO6), pp. 71 - 84, Oct. 2006,

[7] http://www.caida.org/tools/utilities/netgeo

[8] http://www.ip2location.com/

[9] http://www.maxmind.com/app/ip-location

[10] D. Zeinalipour-Yazti, V. Kalogeraki, and D. Gu nopulos, "pFusion: A P2P Architecture for Internet-Scale Content-Based Search and Retrieval.", IEEE Transations on Parallel and Distributed Systems, Volume. 18, No. 6, pp. 804-817, Jun. 2007.

[11] X. Sun, K Li, and Y. Liu. "SLUP: a semanti c-based and location-aware unstructured P2P 
Network", Proc. of the 10th IEEE International Conference on High Performance Computing and Communications (HPCC '08), Dalian China, pp. 288-295, Sep. 2008

[12] Y. Liu, L. Guo, F. Li, and S. Chen, "A Case Study of Traffic Locality in Internet P2P Live Streaming Systems," Proc. Distributed Computing Systems, pp. 423-432, Jun. 2009.

[13] M. Alhaisoni, A Liotta, and M. Ghanbari, "An assessment of Self-managed P2P Streaming," Proc. Conference on Autonomic and Autonomous Systems, pp. 34-39, Apr. 2009.

[14] D. Tran, K. Hua, and T. Do, "ZIGZAG: An Effic ient Peer-to-Peer Scheme for Media Streaming.", Proc. IEEE INFOCOM, pp.1283-1292, Apr. 2003.

[15] M Castro, P. Druschel, A Kermarrec, A Nandi, A Rowstron, and A Singh, "SplitStream: High-Bandwidth Multicast in Cooperative Environments.", Proc. ACM SOSP, pp.298-313, Dec. 2003.

[16] A. Mondal, Y. Lifu, and M. Kitsuregawa. "P2P R-Tree: an R-Tree-based Spatial Index for Peer-to-Peer Environments.", Proc. EDBT Workshops, pp.516-525, Nov. 2004

[17] X. Hei, C. Liang, J. Liang, Y. Liu and K Ross, "A Measurement Study of a Large-Scale P2P IPTV System”, Proc. IEEE Multimedia, vol. 9, no. 8, pp.1672-1687, Dec. 2007.

[18] X. Liao, H. Jin, Y. Liu, L. M Ni, and D. Deng, "AnySee: Scalable Live Streaming Service based on Inter-Overlay Optimization.", Proc. IEEE INFOCOM, pp.1663-1674, Apr. 2006.

[19] X. Zhang, J. Liu, B. Li, and T. P. Yum, "CoolStr eaming/DONet: a Data-driven Overlay Network for Peer-to-Peer Live Media Streaming.", Proc. IEEE INFOCOM, pp.2102-2111, Mar. 2005.

[20] Z. Li, J. Cao, and G. Chen, "ContinuStreaming: Achieving High Playback Continuity of Gossip-based P2P Streaming.", Proc. IEEE IPDPS, pp.1-12, Apr. 2008.

\section{저 자 소 개}

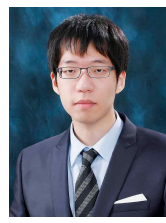

김 태 영

2011 : 홍익대학교 컴퓨터공하과 학사

현재 : 홍익대학교 컴퓨터공학과 석사 과정

관심분야 : $\mathrm{P} 2 \mathrm{P}$ 비디오 스트리밍 시

스템, IPTV 시스템

Email : kimty0909@naver.com

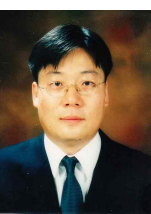

김 은 삼

1994 : 서울대학교 컴퓨터공하과 학사 1996 : 서울대학교 컴퓨터공학과 석사 1996-2002 : LG전자 선임연구원

2006 : Univ. of Florida 컴퓨터공 학과 박사

현재 : 홍익대학교 컴퓨터공학과 조교수 관심분야 : 분산 멀티미디어 시스템, IPTV 시스템, 컴퓨터 저 장시스템

Email : eskim@hongikac.kr 